\title{
Entre formigas e estrelas
}

\author{
Vinicius Prates
}

LATOUR, B.

Reagregando o social:

uma introdução à teoria do ator-rede.

Salvador: EDUFBA-Edusc, 400 p., 2012.

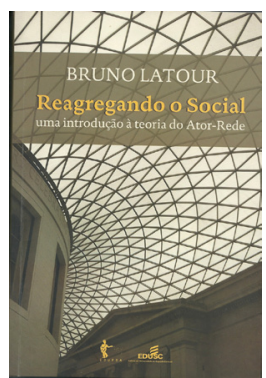

Resumo: Esta resenha apresenta o livro Reagregando o social: uma introdução à teoria do ator-rede, última obra do filósofo francês Bruno Latour publicada no Brasil. Nele, o autor se propõe a elaborar uma suma da crítica que faz aos conceitos usualmente aceitos de "social", o que vem desenvolvendo ao longo dos últimos anos de produção intelectual. Neste processo ele criou a "Teoria-ator-rede", que busca reestabelecer teoricamente as relações entre o que chama de mediadores "humanos" e "não-humanos".

Palavras-chave: Teoria ator-rede, sociologia das associações, mediadores, intermediários, Bruno Latour.

Abstract: This review presents the book Reassembling the social: an introduction to the actor-network-theory, the most recent work of the French philosopher Bruno Latour published in Brazil. In this book the author proposes to create a resume of his critics to the usually applied concepts of "social", which he is being developing during the last years of his intellectual production. In this process he creates the "Actor-network-theory", that aims to rebuild theoretically the relations between what he calls "humans" and "non-humans" mediators.

Key-words: Actor-network theory, sociology of associations, mediators, intermediaries, Bruno Latour.

O livro Reagregando o social, lançado em 2012 pelas editoras da Universidade Federal da Bahia e da Universidade do Sagrado Coração, de Bauru, tem um subtítulo explicativo: Uma introdução à teoria do ator-rede. Nele, Bruno Latour procura condensar 
uma trajetória intelectual que o tornou um dos autores mais influentes da atualidade, já a partir da publicação na França de Jamais fomos modernos, em 1991, obra traduzida para 22 idiomas $^{1}$ (inclusive para o português, pela Editora 34, em 1994). Desde então, Latour vem a cada nova publicação investindo no desenvolvimento de aspectos da teoria ator-rede, que propõe uma reformulação do debate sobre "o social". A versão da EDUFBA e da Edusc chega com sete anos de atraso em relação à original, escrita em inglês, língua usada pelo autor nos últimos livros; ele é nascido na região francesa da Borgonha. Desde então, outras duas obras já foram lançadas por Latour e aguardam edições em português: Cogitamus (2010) e On the modern cult of fact gods (2009), sem falar ainda em An inquiry into modes of existence, que está no prelo. A iniciativa das editoras baiana e paulista, neste caso, deve ser saudada pelo mérito de diminuir um pouco o atraso em relação à produção do autor; mesmo assim, permanece necessário mencionar que o texto é pontuado por falhas de revisão, menos graves, contudo, que a falta de informações sobre a publicação original na ficha técnica, principalmente ao levar em conta que esta é uma obra destinada ao leitor acadêmico.

Reagregando o social se inicia com Latour dizendo qual sua pretensão com a teoria ator-rede, que será explicada ao longo do volume:

O argumento deste livro pode ser definido de maneira simples: quando os cientistas sociais acrescentam o adjetivo "social" a um fenômeno qualquer, aludem a um estado de coisas estável, a um conjunto de associações que, mais tarde, podem ser mobilizadas para explicar outro fenômeno. [...] O que tenciono fazer no presente livro é mostrar por que o social não pode ser construído como uma espécie de material ou domínio e assumir a tarefa de fornecer uma "explicação social" de algum outro estado de coisa (LATOUR, 2012, p. 17-18).

O autor compara o momento vivido pelas ciências sociais ao da física no início do século passado, quando as modernas concepções da disciplina abandonavam a hipótese da existência do "éter", uma substância ubíqua do cosmo, e adotavam uma concepção relativista. Pois, para ele, "o social" é metaforicamente representado por esse éter, espécie de substância unificadora que está "por trás" ou "acima" de tudo, mas que permanece indefinida. Latour propõe que se passe de uma "sociologia do social" para uma "sociologia das associações".

Para ele isso ocorreria se assumida como tarefa das ciências sociais a revisão das muitas tentativas de enquadramentos generalizantes que permitem saltos entre o "local", ou "micro", e o "global", ou "macro". O "social" seria maleável o suficiente para justificar essas manobras acrobáticas, diferentemente das "associações", que descreve da seguinte maneira:

1 De acordo com o website do escritor: <www.bruno-latour.fr $>$. 
Os sociólogos do social parecem pairar como anjos, transportando poder e conexões quase imaterialmente, enquanto o estudioso da ANT tem de arrastar-se como uma formiga, carregando seu pesado equipamento para estabelecer até o mais insignificante dos vínculos (p. 47).

Como vimos, a teoria ator-rede assume em inglês o acrônimo ANT, língua na qual esse também é o significante para "formiga", duplicidade com que Latour joga ao longo do livro. Os pesquisadores ANT são aqueles que se arrastam penosamente por finos fios condutores pelos quais objetos e humanos se associam, evitando a tentação de "pegar carona" nas generalizações e assim cumprir o trajeto da pesquisa "rápido demais".

A "sociologia das associações" propõe que esses pequenos fios que representam os vínculos entre atores, e que formam a figura da rede, se deem a partir do nivelamento ou achatamento das perspectivas hierárquicas anteriormente propostas pela "sociologia do social". Assim para Latour se constrói a imagem de um social em rede - mediante a especificidade de cada associação. As redes, portanto, não são substantivas, de forma que a ANT descarta a concepção de "duras" estruturas preexistentes como as construídas para o transporte metroviário ou para o saneamento hidráulico, nas metáforas do escritor.

Para ele essa é a garantia contra o uso da figura do "intermediário", elemento criado pela "sociologia do social" para cumprir um papel muito pobre: ser aquele que "transporta significado ou força sem transformá-los" (p. 65). Pelo contrário, quando um pesquisador se comporta como ant, palmilhando os caminhos tortuosos e precários das redes, passa a perceber humanos e objetos também como "mediadores", ou seja, atores que têm presenças importantes nas associações, e cujas especificidades têm de ser levadas em conta.

Por esse ponto de vista, os atores que realizam as associações não são menores ou maiores que outros, não são englobados nem englobam, mas se valem de interações mais ou menos numerosas, mais ou menos firmes. Com o "achatamento", desaparecem as imagens de esferas sociais e surgem atores em formatos de "estrelas", com seus raios prolongando-se por várias direções, conforme cada uma das interações, algumas delas provavelmente inusitadas. Cabe às "formigas" da teoria ator-rede seguir com paciência esses raios, ater-se aos mediadores, ouvir o que têm a dizer, sem as generalizações apressadas que os tornariam calados intermediários.

Um livro que procura explicar a integralidade da teoria ator-rede pode ajudar alguns leitores que conhecem apenas um tópico de Latour, talvez o mais exótico à primeira vista, a compreendê-lo em seu contexto: as estranhas formações de "assembleias" que congregam humanos e objetos.

O autor trabalha com metáforas emprestadas da política desde Jamais fomos modernos. Àquela altura Latour já falava de uma "constituição" da modernidade, formada na separação entre a física de Robert Boyle (1627-1691) e a filosofia de Thomas Hobbes (1588-1679). Nas experiências com complicadas bombas de vácuo apresentadas na 
corte britânica, Boyle estabeleceu a crença de que a natureza "fala" de uma maneira mais confiável do que os humanos. As experiências científicas que se inauguram nesse período vão promover, de acordo com o livro, uma divisão radical entre a natureza, que é convocada pelos cientistas a atestar a verdade, e o caótico reino da cultura: por um lado as coisas-em-si, por outro os humanos-entre-eles.

A partir desse ponto Latour descreve a modernidade como impulsionada por uma força motriz da purificação entre as duas esferas, num trabalho obsessivo de livrar-se do horror dos híbridos. Inglório trabalho, já que eles continuam a aflorar por todos os lados e a se tornar mais complexos. Já a partir de Jamais fomos modernos, mas também no posterior Políticas da natureza, ele descreve como os discursos ecologistas são fontes privilegiadas de hibridação, capazes de unir num mesmo texto - por exemplo, sobre as ameaças à camada de ozônio - sindicatos, leis, aerossóis, moléculas de CFC e a Organização das Nações Unidas: tudo ao mesmo tempo natural, social e narrado.

Políticas da natureza foi publicado na França em 1999 e no Brasil pela Edusc em 2004. Nessa obra, de título um tanto anódino (ao contrário da publicação que o havia tornado famoso), o autor acrescenta um instigante subtítulo: Como fazer ciência na democracia. Nesse caso, deve-se estar preparado para mais uma metáfora política. Não se trata certamente da democracia formal, aquela que se constituiu no discurso da modernidade conjuntamente com o método científico. O que Latour busca é um regime que reúna os "quase-objetos" e os "quase-humanos": natureza e sociedade numa organização "bicameral".

E todos esses pontos um tanto estranhos levantados em obras anteriores são explicados nesta súmula que se pretende Reagregando o social. Para que as "assembleias" façam sentido, a principal mudança postural do pesquisador deve ser perceber a manifestação, a fala dos não humanos. Na verdade, a teoria ator-rede argumenta àqueles que acham essa posição exótica que eles fazem isso o tempo todo, mas não são ouvidos. Aquilo (aqueles) que é (são) considerado(s) pela "sociologia do social" coisas-em-si ou humanos-entre-eles, no interminável cumprimento da constituição moderna, deve $(\mathrm{m})$ pela "sociologia das associações" ser considerado(s) ator(es) de uma rede, no seguinte sentido:

Se você puder, com a maior tranquilidade, sustentar que pregar um prego com ou sem um martelo, ferver água com ou sem uma panela, transportar comida com ou sem um cesto, andar na rua com ou sem roupas, zapear a televisão com ou sem o controle remoto, parar um carro com ou sem o freio, fazer um inventário com ou sem uma lista, administrar uma empresa com ou sem a contabilidade são exatamente as mesmas atividades, que a introdução desses implementos comuns não muda nada "de importante" na realização das tarefas, então você está pronto para visitar a Terra Longínqua do Social e desaparecer daqui. Para todos os outros membros da sociedade esses implementos fazem muita diferença e são, pois, segundo nossa definição, atores - ou, mais exatamente, partícipes no curso da ação que aguarda figuração (p. 108). 
Ocorre que para a sociologia proposta pelo autor, não humanos podem também se comportar como "mediadores", ou seja, atuar transformando de maneiras surpreendentes "força ou significado", por vezes mais que humanos eventualmente tratados como "intermediários" pela "sociologia do social". E aqui está uma chave de leitura de sua obra que emerge com força nesta última publicação. Martelo, panela, comida, roupas, controle remoto etc. não são "objetos" no uso corrente do termo, ou o que Latour chama de "intermediários". Eles assumem na associação papéis de "mediadores" quando modificam relações de forças, geram significados.

Sem dúvida, neste e em outros exemplos, Latour tem seu léxico, e só é possível uma aproximação com o escritor após apreendê-lo minimamente. Isso já é visível no índice da obra, dividida em duas partes, chamadas Como desdobrar controvérsias sobre o mundo social e Como tornar as associações novamente rastreáveis. Para citar alguns títulos de capítulos, ordenados de acordo com o que o autor considera "fonte de incerteza", temos "Como se alimentar de controvérsias", "Os objetos também agem" ou "Escrever relatos de risco", todos da primeira parte. Na segunda, o destaque fica para os capítulos que propõem "localizar o global" e "redistribuir o local", além da conclusão, chamada "Da sociedade ao coletivo - o social pode ser reagregado?".

Pesquisadores brasileiros ganham com esta edição a rara oportunidade de ter acesso ao compêndio de uma teoria recente escrito por seu criador e principal postulante. Ganham, ainda, um pequeno presente: no meio do livro há um interlúdio em forma de diálogo de pouco mais de vinte páginas na qual um experiente (e um tanto enfadado) professor recebe um ansiosíssimo aluno de doutorado que lhe pede para explicar como usar a teoria ator-rede. Quem já esteve de algum desses dois lados em qualquer curso de pós-graduação não tem como não se identificar com os personagens. E se divertir.

Vinicius Prates é jornalista, professor universitário e doutorando no Programa de Estudos Pós-Graduados em Comunicação e Semiótica da PUC-SP com bolsa do CNPq>. viniciusprates.vp@gmail.com

\section{Referências}

LATOUR, Bruno. Jamais fomos modernos. São Paulo: Editora 34, 1994.

Políticas da natureza. Bauru: Edusc, 2004. 